\title{
Global platforms and asymmetrical power: Industry dynamics and opportunities for policy change
}

new media \& society

\section{Karoline Andrea Ihlebæk}

Oslo Metropolitan University, Norway

\section{Vilde Schanke Sundet}

University of Oslo, Norway

\begin{abstract}
Global platforms have radically changed institutional dynamics within the media industry. In this study, we explore how national media organisations manoeuvre in an increasingly uneven playing field. Combining theoretical perspectives from platform studies and the media policy field approach, we analyse how asymmetrical platform power impacts industry-policy relations in a small-nation context. We find that national players collectively frame the power of global platforms as a potential threat to the media sector and to democracy. In this framing, all the players - regardless of size or market position - define themselves as 'small' to signal a common threat and mission across the industry. Being 'small' however does not entail the same for all players, which results in different action logics. We also find that industry players use collective framing to protect existing support schemes and to legitimate the call for new ones, while they seek international collaboration to impact regulation of global platforms.
\end{abstract}

\section{Keywords}

Facebook, industry, media policy field, platforms, policy, power, regulation, small nations

\section{Corresponding author:}

Karoline Andrea Ihlebæk, OsloMet - Oslo Metropolitan University, P.O. Box 4 St. Olavs plass, Oslo, Oslo N-0I30, Norway.

Email: ihlebaek@oslomet.no 


\section{Introduction}

The power of global platforms, such as Facebook and Google, has increasingly become the subject of public and scholarly scrutiny (Andrews, 2019; Evens and Donders, 2018; Mansell and Steinmueller, 2020; Van Dijck et al., 2018). Research has shown how global platforms radically change institutional dynamics, including the media, and how national media organisations struggle to cope with what has increasingly become an uneven playing field (Nielsen and Ganter, 2018). For national players, a central dilemma has been the question of how to utilise the opportunities offered by the new platform technology while staying in control, protecting revenues and retaining the audience's trust (Meese and Hurcombe, 2020). The asymmetrical power relations that occur when global companies enter national markets are arguably even more profound for media players in small nations, as their operation lacks the benefits of economies of scale even without competition from global platforms (Doyle, 2013). A core question in this context is what 'small' means. As Puppis (2009) points out, indicators like territory, economics and population size can be useful measurements in this regard, but the latter is particularly fruitful to define small nations in a media policy context because it is understood to influence industry-policy relations. ${ }^{1}$ This article analyses how platform power impacts the media field, as seen in the context of a small nation. Two research questions guide the article:

$R Q 1$. How do media players frame the main challenges of global media platforms?

$R Q 2$. How do new power dynamics in the media field create opportunities for industry and policy change?

The article draws on a case study of the Norwegian media market. Although the Norwegian market is small in terms of population size (5.3 million people), it is also a wealthy country, it is technologically mature and it has served as a strategic test market for many global platforms and social media providers. Trends in this market may therefore serve as forecasts for other markets as well. Furthermore, platform power is high on the agenda in Norway and has been the subject of industry and policy debates (Enli et al., 2019; Sjøvaag and Krumsvik, 2017; Sundet et al., 2020). Methodologically, the article builds on data from 14 elite interviews with $\mathrm{CEO} /$ top management leaders representing the largest media institutions, media owners and media interest organisations in the country, as well as document analysis of relevant policy and industry texts.

Theoretically, the article combines insights from platform studies (Gillespie, 2010, 2018; Van Dijck et al., 2018) with the media policy field (MPF) approach (Steen-Johnsen et al., 2019). Platform studies provide an overall framework for addressing changing power dynamics on a societal, cultural and political level. The MPF approach offers a framework for analysing policy-industry relations by focusing on three points: collective frames, incumbent and challenger roles and policy windows. We argue that a combined perspective gives us the tools for exploring how media players manoeuvre in a disruptive field, what skills they use to defend positions and how industry actions are contextualised by more deeply entrenched platform structures.

A key argument in the article is how the MPF approach constitutes a fruitful starting point for critically exploring how asymmetrical power is encountered in more detail. In 
the study, we find that incumbent actors in the market actively define themselves as 'small'. 'Smallness' is at one level collectively framed around the notion of how global platforms represent a common threat to the national media market, which in turn represents a danger to the Norwegian welfare state and democracy. This collective frame has opened policy windows for expanding and strengthening national policy incentives. At another level, being 'small' does not entail the same things for all national players, and diverging strategies are employed. Size and market positions impact how industry players act, both in terms of how they envisage collaborations with global platforms and how they position themselves against each other. The latter is particularly visible when it comes to how private media companies use the situation to criticise the privileged position of the public service broadcaster that employs digital platforms actively to distribute its content. At the same time, it is important to acknowledge that many of the challenges envisaged are not specific to being a 'small nation'. This is particularly the case when it comes to the perceived difficulties of regulating them. The problems lie in the asymmetries of scale between any single nation and big tech companies. Consequently, the problem formulations and the action frames found in this study can be generalisable to other countries as well. ${ }^{2}$

\section{Platform power and the media}

A core element of platform studies is addressing platform power and how it impacts societal, economical, cultural and political dimensions nationally and internationally (Bucher, 2018; Galloway, 2017; Gillespie, 2018; Plantin, 2019; Plantin et al., 2018; Srmicek, 2017; Van Dijck et al., 2018). To explore responses to platform power, it is necessary to define what we mean by 'platforms'. As pointed out by Gillespie (2010), Mansell and Steinmueller (2020) and others, the term has several meanings in different fields, and it has changed historically (see Steinberg, 2019). In the context of this article, we refer to digital platforms as 'technology geared toward the systematic collection, algorithmic processing, circulation, and monetization of user data' (Van Dijck et al., 2018: 4). An important insight promoted by several scholars is that platforms should not be understood solely as hardware, but also in terms of how platforms are intertwined with the corporate sphere and cultural and political values. Control of these platforms is currently situated in the hands of a few 'super players', of which Google (Alphabet), Apple, Facebook, Amazon and Microsoft are the most important (Van Dijck et al., 2018: 3). The companies represent, according to Jin (2020), a 'great source of power to the United States over other countries' (p. 5) and constitute the core of what Van Dijck et al. (2018) have termed the 'platform society' (p. 2).

From a media studies perspective, scholars have analysed how global platforms influence the media field (Andrews, 2019; Enli et al., 2019; Meese and Hurcombe, 2020; Nielsen and Ganter, 2018). Scholars have charted the effect digital platforms have on market dynamics and how national players respond to asymmetrical power (Evens and Donders, 2018; Flew et al., 2016). It has been duly documented that platforms have disrupted the advertising sector, severely impacting national media economies, but also how they offer efficient new services for personal advertising and distribution of content (Lobato, 2019; Ots and Krumsvik, 2016; Sjøvaag and Krumsvik, 2017). Media 
organisations have become increasingly dependent on global platforms, and many companies have been keen to utilise their services even though it comes with certain risks (Meese and Hurcombe, 2020; Rashidian et al., 2019). Nielsen and Ganter (2018) identify tensions between media institutions' 'short-term operational' and 'long-term strategic considerations' when utilising 'digital intermediaries' (p. 1607). These tensions are often the result of the asymmetrical power relationship that makes the conditions for collaboration unclear, in particular when it comes to ownership of data (p. 1611). A recent study of the Australian news market by Meese and Hurcombe (2020) shows how media organisations can be characterised by different levels of platform dependency, which again impacts how national news institutions strategise to utilise Facebook's algorithms (p. 11).

While individuals and commercial and public actors benefit from efficient distribution channels and tailored information, a core question in the last decade has been how platforms can be governed and regulated both nationally and internationally to prevent negative consequences of platform power (Cammaerts and Mansell, 2020; Flew et al., 2016; Gillespie, 2018; Mansell, 2021; Van Dijck et al., 2018). Although platforms increasingly engage in self-regulation strategies to avoid state intervention, interference at the EU level to protect public values, such as privacy and freedom of expression, has become fiercer (Mansell, 2021). Recent antitrust lawsuits in the United States to hinder anti-competitive practices and suggestions of a global minimum tax also predict a more offensive regulatory approach. While small nations have seemed dependent on intranational solutions to prevent the harmful sides of global platform power, several recent developments in for instance France, Germany and Australia, suggest that regulation of platforms is possible at a national level. Flew et al. (2016) have also pointed out that national governments still play a crucial role in shaping the media sector through national and sector-specific policy incentives. Securing national language, culture and diversity has been an important goal for media regulation and has been used to legitimise economic support schemes in small nations. Also, policy formation in small nations benefits from collaboration and consensus among small elites (Puppis, 2009: 9).

\section{The MPF approach}

While platform studies provide an overall framework for addressing changing power dynamics, the MPF approach offers a more focused account for analysing changing policy-industry relations within a field (Steen-Johnsen et al., 2019). It combines lessons from organisational field approaches (the theory of strategic action fields; Fligstein and McAdam, 2011) with a theory of policy development (the multiple streams approach; Kingdon, 1995) to address change in the media field. It does not address change from the viewpoint of any singular institution but zooms in on the relationship between actors and investigates how they adapt to the actual or perceived actions of each other (DiMaggio and Powell, 1983; Lawrence and Suddaby, 2006). The MPF approach proposes three interrelated analytical focal points: the construction and strategic role of collective frames, the dynamics between incumbents and challengers and the possibility for policy windows (Steen-Johnsen et al., 2019). 
The focus on collective frames emphasises that underlying any field is a set of commonly shared frames that defines the aims, relationships and rules, which, under the pressure of disruptive change, are expected to become increasingly contested (Fligstein and McAdam, 2011). Thus, to understand industry-policy relations, there is a need to investigate the different action logics and action frames that have currency in the field and trace their transformation and the emergence of new ones (Steen-Johnsen et al., 2019; see also Freedman, 2010). In our case, the focus on collective frames implies paying attention to how national industry players define the problems (and opportunities) of global platforms as well as the solutions these players promote. Previous studies have shown that national media organisations tend to frame themselves as a democratic safeguard (Brüggemann et al., 2016; Enli et al., 2019; Evens and Donders, 2018; Sundet et al., 2020; Sundet and Syvertsen, 2021). A criticism of the study of collective frames is how it might enhance problem definitions and understandings that unify players in a field with the risk of neglecting divergent positions. We try to accommodate this apparent weakness by emphasising how collective frames are used simultaneously within and across industries to achieve specific goals.

The focus on incumbent and challenger roles highlights the way that power structures in a disruptive field may be changing and unstable and how new forms of strategic alliances may emerge. 'Incumbents' are regarded as organisations and institutions that are well established within a field and benefit from current political and economic arrangements within it. 'Challengers' occupy less-privileged positions and usually have little influence over the field's operation. Typical examples of incumbents are legacy news media and public service institutions. However, both 'incumbent' and 'challenger' are defined relative to each other, meaning that who these terms include depends on market definitions. Nevertheless, for both incumbents and challengers, the MPF approach stresses the importance of social skills - that is, the cognitive capacity to develop frames that resonate with distinct groups and serve as tools for mobilisation within a given field (Steen-Johnsen et al., 2019; see also Fligstein and McAdam, 2011). In our case, the focus on incumbent and challenger roles implies attending to who says what with what interest and looking for strategic alliances, partnerships and cooperation. Previous studies have shown that incumbent media players are increasingly joining forces and activating 'converging frames' that include several industry problems to initiate and influence media policy actions (Sundet et al., 2020).

Finally, the focus on policy windows highlights how key stakeholders and so-called 'policy entrepreneurs' may take advantage of the opening of possibilities for forming a new policy in times of change. Policy windows exist when a problem is being singled out as important, a policy solution is available and the political climate is pro-change (Kingdon, 1995). As stressed by Zahariadis (2014), policymaking is characterised by ambiguity and complexity where policymakers work with multiple problems at the same time. Framing a problem and a given solution in a way that gains attention and seems efficient is vital to promoting change. In this study, the focus on policy windows implies paying attention to situations in which media players use collective frames about platforms to enhance policy solutions that seem beneficial to them. Previous studies have shown that incumbent media organisations are surprisingly resourceful when trying to impact media policy work, specifically in small nations where bonds between elites are 
close, and that economic measures to safeguard small media markets have been relatively common (Freedman, 2008; Puppis, 2009).

\section{Case and method: studying asymmetrical platform power}

The article builds on a case study of a small nation's response to the increasing power of global platforms using the Norwegian media market as the basis for analysis. The Norwegian media model is often described in terms of the northern European democratic corporatist model (Hallin and Mancini, 2004), characterised by the broad reach of the press market, high degrees of political parallelism, substantial professionalisation and extensive state intervention in the form of strong public service broadcasters and subsidies for the press. In the context of this study, two aspects of the Norwegian model should be pointed out. First, public policy measures are crucial to media development, leading to media industry players paying significant attention to media policy. Second, the model exhibits strong corporatist traits, which means that central media players are invited to participate in all major policy processes (Syvertsen et al., 2014).

The article's data consist of 14 elite interviews with Norwegian CEO/top management media industry leaders (see Table 1$){ }^{3}$ Interviewing industry elites is a valuable method for gaining in-depth insight into industry perceptions and strategies, which often can be hard for researchers to attain through other sources or methods. Elite informants are also helpful in interpreting institutional and political documents and processes (Van Audenhove and Donders, 2019; Richard, 1996). All the same, elite interviews require critical analysis, as these informants represent leading and powerful positions and typically present arguments that reflect corporate interests.

The informants were selected to represent the most prominent national media companies and are categorised as follows: media groups (Schibsted, Aller and Amedia), broadcasters (NRK and TV 2), newspapers (VG, Dagbladet and Aftenposten) and interest and industry organisations (Association for Media Businesses [MBL], Association of Editors [NR], Norwegian Producers Association, and Tinius Trust). The study also includes one interview with Facebook, the only platform provider that responded to our interview request. ${ }^{4}$ All the interviews were conducted in the spring 2019, that is, in the aftermath of the Cambridge Analytica scandal that amplified the call for increased governance of platforms (Mansell, 2021). The interviews followed a shared, semi-structured interview guide, slightly adjusted to accommodate the informants' distinct roles and positions. More specifically, we asked informants to describe the critical challenges and opportunities of global platforms as well as industry and policy solutions they found suitable for solving industry problems. All the interviews were transcribed and thematically analysed (Herzog et al., 2019) according to the informants' responses to questions related to perceptions of challenges (problem definitions) and action frames (solutions).

The article also relies on document analysis (Karppinen and Moe, 2019) of relevant policy and industry texts, most notably a green paper on media diversity (NOU, 2017:7), a white paper on media policy (Meld. St. 17 [2018-2019]), two white papers on public service broadcasting (Meld. St. 15 [2016-2017]; Meld. St. 38 [2014-2015]) and submissions from stakeholders to public hearings on these policy papers (see reference list for 


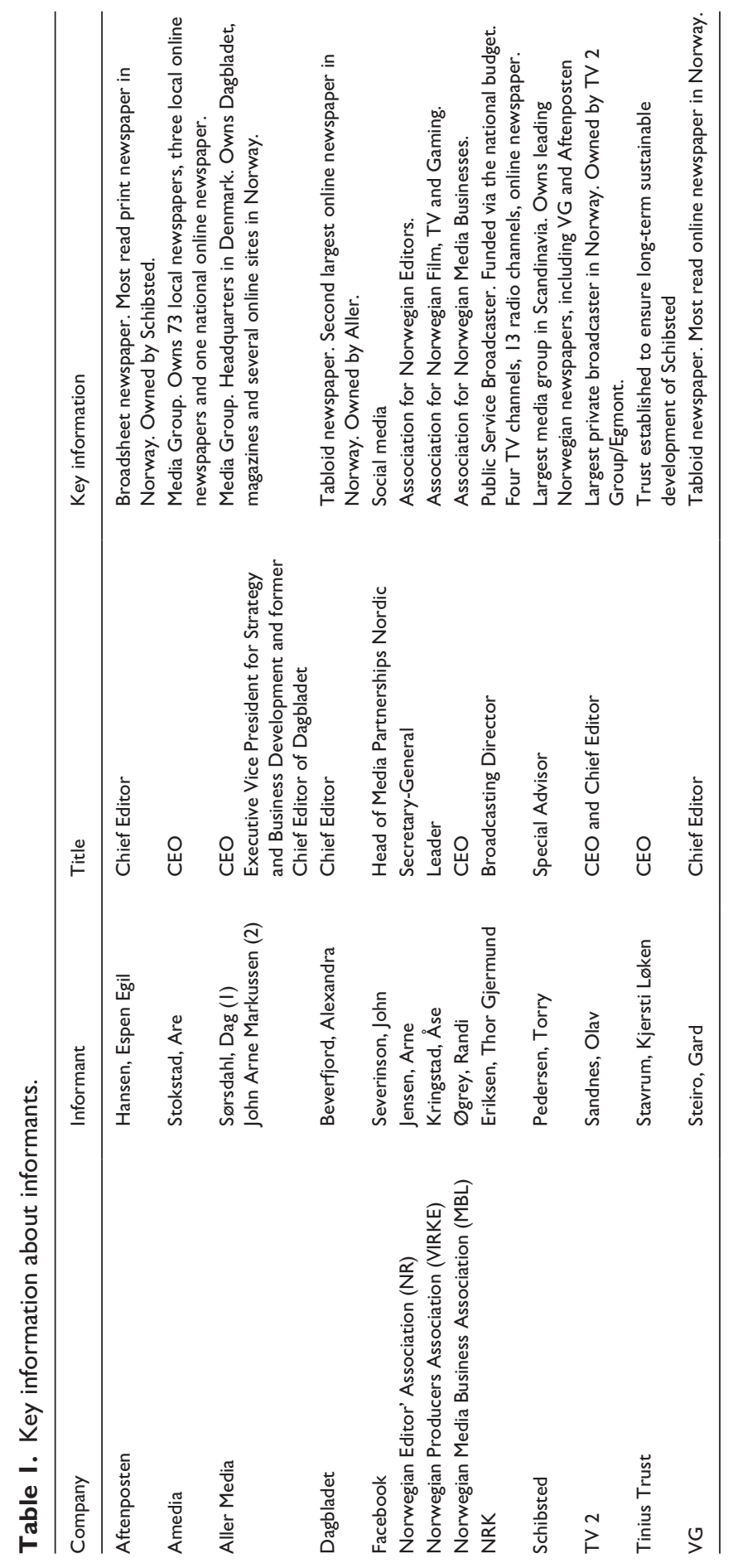


an overview). We use these documents to identify policy windows, contextualise interview statements and relate them to media policy processes.

\section{Constructing collective frames: 'in the big sea, we are a small fish'}

Our study shows that it was widely accepted that platforms had become a necessary part of the infrastructure in Norwegian society and the media industry. Several policy documents reflect this perspective as well (Meld. St. 17 [2018-2019]: ch. 2; NOU, 2017:7: 65-66). At the same time, global platforms and the kind of power they represent were seen as a threat not only to the national media industry but also to Norwegian culture and democracy, which depends on a well-functioning media sector. More specifically, informants highlighted how platform power constituted a threat to the issue of trust and ownership of user data - perceived to be 'the new oil' of the industry. Many informants also stressed that global platforms evaded tax in national markets and therefore failed to contribute to the Norwegian welfare state, while they at the same time severely impacted the national advertising market. Similar perspectives can also be identified in public and industry reports, stressing how global platforms continuously increase competition in the Norwegian market (Meld. St. 17 [2018-2019]: 6; see also NOU, 2017:7). To comprehend the complicated relationship to global platforms, several informants used the term 'frenemies', describing global platforms at once as both friends and enemies. Furthermore, platform owners are expected to be even more powerful in the future. As the leading tabloid VG framed it, 'When the next wave of technology or paradigm shift takes place (. . .) the global actors will be even more powerful gatekeepers than today' (VG, interviewed 2019). Consequently, the challenges of asymmetrical power are contextualised as a short-term and a long-term problem (see Nielsen and Ganter, 2018).

A key finding from reviewing our informants' descriptions of challenges with platforms is how they emphasise the negative effects of asymmetrical power through collectively repositioning themselves from being 'big' in the national market to 'small' in the worldwide market. The informants frequently reflected this re-definition in the context of an extended market through phrases such as, 'We are very small - the Norwegian media market is piccolo in comparison to the global' (MBL, interviewed 2019), 'This is not a Norwegian Championship anymore, it is the World Championship' (TV 2, interviewed 2019) and 'We are big on a Norwegian scale, but tiny in comparison to techcompanies such as Google' (Amedia, interviewed 2019). Relatedly, several informants stressed the importance of widening the perspective from a national to a global scope to reflect the entire competitive landscape. The public service broadcaster NRK argued,

The main problem with the Norwegian debate is that perspectives are too self-centred and fail to cover the actual situation. (. . .) Norwegians live in a global media world, while we keep discussing it as if it was a Norwegian media world. (NRK, interviewed 2019)

Similarly, the commercial broadcaster TV 2 stressed the conceptual challenge of redefining oneself as 'small' when one used to be 'big': The transformation of TV 2 s competitive position, going from being 'the big fish in a small pond' to a 'small fish in a big 
sea', also required a cultural change in the organisation (TV 2, interviewed 2019). 'Being small' is, of course, a relative term and arguable; all national actors across the globe can be described as 'small fish' compared to digital platforms with a global reach. In the following, we will explore in more detail how understandings of asymmetrical power and definitions of 'being small' represent specific action logics that impact both industry relations and calls for policy incentives.

\section{Industry solutions and level of dependency: 'we had to act opportunistically'}

A key priority for incumbent actors in the media sector has been to evaluate the best moves towards global platforms and to develop the necessary skills to tackle challenges. 'Skills', in this context, refers to the capacity to utilise specific action logics within a given field (Steen-Johnsen et al., 2019; see also Fligstein and McAdam, 2011). As such, strategy work is intricately linked to finding solutions to defined industry problems.

In general, becoming too dependent on global platforms was perceived as risky among all informants. For instance, the Association for Media Businesses (MBL) emphasised that entering a close relationship with global platforms is hazardous because they cannot be trusted: 'Trust is hard to get and easy to lose' (MBL, interviewed 2019). Facebook was often mentioned as the most problematic platform and referred to as 'probably the worst in class' (Tinius, interviewed 2019). The Cambridge Analytica scandal was used as a common reference point, illustrating how such controversies and misuse of trust made it impossible for Norwegian players to close their eyes to Facebook's operations. Relatedly, many informants expressed fear that users' lack of trust in Facebook would transfer to a lack of trust in them and, even more fundamentally, a lack of trust in the media's democratic role. This, they argued, would call into question not only media as an industry, but pose a risk to society and democracy at large. While there existed a general scepticism towards platforms and the power they represent, all the industry players in our study were nevertheless to some degree dependent on platform services. Yet the level of platform dependency differed significantly among companies. We can crudely distinguish between those who used global platforms predominantly to distribute content and those who engaged into closer ventures. We find that these strategies are applied by players rooted in both news and broadcasting.

Turning to the broadcasters first, we find both the public broadcaster NRK and the private broadcaster TV 2 to share a similar vision of their newly attained role as 'small', although their approaches to platform collaborating are quite different. TV 2 took the restrictive approach and emphasised the danger of becoming too dependent on global platforms, for example, deciding not to use YouTube to share content and following a restrictive line with Facebook as well. Instead, TV 2 stressed the importance of entering close collaborations and partnerships with other players in the film, television and gaming industry, including NRK, not the least related to acquiring exclusive sports rights and the production of high-budget drama. Nevertheless, TV 2 stressed how, even when collaborating, they fail to combat global streaming platforms because of their size and that 'staying small' represented an alternative strategy that allowed the company to explore a 
new sense of flexibility. Instead of merging with other Norwegian or Nordic broadcasters to become 'less small', TV 2 stressed the benefit of utilising 'being small':

People ask how we can compete as a standalone player and why we don't team up with TV 4 in Sweden and TV 2 in Denmark to get scale. My answer is that this wouldn't help. We would go from being a mosquito to a fly in the international competition, and we would risk using a lot of time coordinating instead of utilising the benefits of being small. (TV 2, interviewed 2019)

Compared to TV 2, the public service broadcaster NRK had a far more explorative strategy and used global platforms extensively to distribute and promote content, particularly youth content (Sundet, 2021). NRK defined its strategy by pointing to its public service mandate, which includes the broad distribution of NRK's services to reach its audiences where they are. For instance, NRK has several YouTube channels and even distinct YouTube programmes, and it has actively used social media, such as Instagram and Facebook, to promote programmes.

This strategy was not without dispute, however, and many media players criticised NRK for using its prominent position to strengthen the competitiveness and attractiveness of global platforms. As argued by the national newspaper Aftenposten, 'NRK has used global platforms, published on them actively, and in doing so, helped to build our main advertising competitor. We believe NRK could and should have made other choices' (Aftenposten, interviewed 2019). TV 2 also questioned NRK's strategy towards global platforms: 'We have for instance questioned why NRK share as much content as they do on global platforms such as Facebook. Through this they are directly fueling advertising dollars to Silicon Valley with license fee-funded content' (TV 2, interviewed 2019). Some informants even questioned the loyalty towards 'we are all small' rhetoric, arguing that NRK should compare itself with other national media instead of global media platforms:

When NRK's Broadcasting Director defines its main competitors to be Netflix and HBO, I beg to ask: Why is it a state-funded task to compete with Netflix? (. . .) We are absolutely not negative towards having NRK as a cultural institution in Norway because NRK is essential, but it is limited how big that institution should be allowed to be. (Aller 1, interviewed 2019)

Hence, while the media players agreed that global platforms represent a common threat, many felt that NRK was not sufficiently fighting the battle but instead strengthening the global competitors. Some claimed that NRK had a more restrictive approach to other national media than it did to global platforms. As formulated by Amedia, 'NRK should be obliged to treat us likewise and give us access to state-funded streams when our global competitors get it' (Amedia, interviewed 2019). NRK, on the other hand, upheld the argument that expansion towards new platforms was a necessity to reach its audience where it is and that the competitive landscape is global, not national. Furthermore, for NRK, the main challenge was cultural, not financial: to protect national language and culture and serve the Norwegian public, NRK insisted on being where the audience is.

Turning to the press sector, we find both strategies applied here as well. The restrictive line was pursued most clearly by the largest media company in Scandinavia, Schibsted, and their newspapers, VG and Aftenposten. According to Schibsted, it was a 
policy decision to avoid close collaborations with global platforms 'to be a trustworthy voice in that debate' (Schibsted interviewed 2019). Likewise, the broadsheet newspaper, Aftenposten, explained how it was crucial to keep a distance: 'We ask ourselves all the time: what strengthens our independency? It is a value we hold high, and it guides our choices' (Aftenposten, interviewed 2019). Admittedly, Aftenposten sometimes used Facebook and other social media platforms to spread content, but according to the informant, this was on a limited scale and primarily to attract people to Aftenposten's website.

The media houses Aller and Amedia decided on a different strategy - to enter into deeper ventures with global platforms for distribution and for advertising. When probed about seeking other alternatives, like collaborating nationally, they pointed to existing market dynamics and positions as a challenge: 'Schibsted is one of the biggest media house in Europe and developed solutions to avoid cooperation with Google. We had to choose a different path' (Aller 1, interviewed 2019). Relatedly, the former chief editor of the national tabloid, Dagbladet, described the decision to collaborate with Google as a necessity and something only larger national companies had the benefit of choosing to avoid:

The financial crisis and the following consolidation in the media sector led to strong growth for Schibsted, and NRK became an even stronger competitor for us operating alone. We tried approaching Schibsted to collaborate, but it didn't lead to anything ... We had to act opportunistically. (Aller 2, interviewed 2019)

Going into closer ventures with global platforms was described as both lucrative, complex and challenging. Informants from Aller and Amedia stressed how platform relations are fraught with uncertainty, as terms and conditions often change rapidly. There is little transparency or predictability about future decisions, again illustrating the asymmetrical power in these relationships. New skills had to be developed, not least because leaders and decision-makers were perceived to be inaccessible: 'To work with Google is worth a study on its own, because there is a long way from Oslo to California' (Aller 1, interviewed 2019). To minimise risk, informants stressed the need for knowing how to navigate the system and identifying the people to contact. Informants also pointed out the importance of intra-organisational solutions and continuously working to develop the necessary technical skills and knowledge about possible collaborators. As explained by Aller, 'We can switch anything anytime because we have the competence to do so' (Aller 1, interviewed 2019). Furthermore, both Aller and Amedia followed a hedging strategy to keep their options open and to avoid being 'held hostage by technology' (Amedia, interviewed 2019). Aller and Amedia also ventured into closer alliances with each other through the company Diar (established in 2019), where they utilise the information gathered through log-in systems to target personalised advertising. Promoting the new service in the press, Aller and Amedia stressed the trustworthiness of their advertising platform: 'We offer advertisers a safe advertising environment with real humans' (Ekeberg, 2019). Even their competitor, Schibsted, envisaged collaboration: 'We are competitors, but we are on the same national team' (Ekeberg, 2019). 


\section{Policy solutions: 'too little, too late'}

Creating change through policy windows involves identifying problems and suitable solutions and having 'entrepreneurs' willing to pursue their goals in a pro-change political climate (Mintrom and Norman, 2009). When asked about possible policy actions against global platform power, informants pointed to two solutions: first, political incentives to protect and strengthen the Norwegian media sector (thus combatting international competition from within), and second, the will and skill to regulate global platforms in terms of taxation (thus creating a level playing field).

Regarding the first issue, informants point to the importance of protecting and expanding media policy measures that had already been implemented at the national level. When asked, most informants describe a good relationship with national politicians, and many appreciated the tradition of consensus-driven policy processes. Many also recognised that the Norwegian media sector enjoys beneficial media policy solutions, explicitly legitimated by the smallness of the market and the state's responsibility in safeguarding democracy (see also Puppis, 2009). For the newspaper industry, the essential measure has been the exemption of VAT for news content and the direct press subsidy, both of which had been expanded from applying to printed press only to covering digital news media as well (NOU, 2010:14, 2017:7). For the broadcasting industry, most of the debate is related to the regulation of public service broadcasting (Meld. St. 15 [2016-2017]; NOU, 2017:7), although initiatives were also made to compel global streaming services to contribute to national markets (AMT directive). In both cases, informants had recent examples of creating policy windows in which they had taken an active part in making these policy changes. Among others, informants had resourcefully monitored and fed their interest into policy debates and accessed policymakers through public consultations, press debates and even public commissions (see, e.g. Amedia, 2017; MBL, 2017; NRK, 2017; Schibsted, 2017). New proposals were also suggested, such as exempting the employers' tax for news organisations and increasing innovation support (NOU, 2017:7); however, these suggestions failed to attain political support.

However, the discussion of national policy regulation was not without tensions, and informants were not always in tune with how to best solve the challenges ahead. One of the most salient issues concerned the remit and financing of the public service broadcaster NRK and the mandate of the NRK, as referred to above. Although the criticism of public service broadcasting is not new in the context of global platforms, it was revisited against a backdrop of immense transformations, an ongoing crisis in both traditional print and commercial broadcasting, and a multitude of complaints about NRK's privileges and duties. NRK stressed that having a reliable public service broadcaster would benefit the national media industry, claiming that 'the day you weaken the political responsibility for the public service broadcaster, you will also undermine the political responsibility for the rest of the media field' (NRK, interviewed 2019; see also NRK, 2017). As identified in other studies, we find that many informants hold a dual position, seeing public service broadcasters both as a problem in terms of competition but also as a solution in terms of collaboration and commissioning (Donders, 2013; Van den Bulck and Donders, 2014). Furthermore, NRK has proven highly skilful in protecting its mandate and position, among others by monitoring and feeding their own interest in public debates and 
accessing policy-makers through public consultations and commissions (Sundet and Syvertsen, 2021). It seems unlikely that the calls for redistributing funding for NRK to other private media or changing their mandate will be effective anytime soon.

Regarding the second issue of platform taxation, informants argued that Norwegian media players and global platforms compete on uneven terms. As one informant put it, 'They came, grabbed advertising, and evaded paying tax . . . We call for more attention to the harmful sides of global platforms' (Tinius, interviewed 2019). While platform disruption in the advertising sector was commonly framed as a challenge, an alternative position would be how media companies already struggled because they could not get audiences to pay for online content. Moving on to digital platforms, Norwegian media organisations, as most media companies in the worlds, struggled to find sustainable business models and faced a crisis (NOU, 2017:7: 9). Google and Facebook in this context offered efficient advertising services, a point that was forwarded by Aller and Amedia. Nevertheless, many informants stressed how the combination of market disruption and lack of taxation is problematic in a two-fold sense, both from an industrial and from a societal-democratic perspective: for national industry players, it means uneven competitive terms; for the society, it means less contribution to the welfare state. As one informant said, 'For our members, it's crucial that major global players like Netflix take part in paying for the feast and help to finance the production of Norwegian content' (Norwegian Producers Association, interviewed 2019). Similarly, another informant stated, 'I believe this is a fundamental democratic question. If companies of this size don't pay tax, it will undermine the financial model we need to support welfare' (Schibsted, interviewed 2019). Policymakers often echoed these sentiments, pointing to global platforms as powerful and hard to regulate (Meld. St. 17 [2018-2019]: 6; see also NOU, 2017:7: 9).

While informants recognised national policymakers' will to protect and expand national media policy measures, less confidence was shown in policymakers' ability to regulate global companies. None of the informants had faith in the Norwegian political system's ability to enforce the tax payments of global companies in the national markets. A main reason for the informants' distrust was the complexity of the issue, which required national politicians to have deep and detailed knowledge of an incredibly multifaceted field. As one informant said, 'They represent a kind of power that we have not seen before [. . .], and it's an obvious challenge for the political field' (Aftenposten, interviewed 2019). Relatedly, another informant stressed, 'The main challenge with the media policy in recent years is that policymakers have failed to grasp the changes soon enough. The policy measurements are too little, too late' (VG, interviewed 2019). Others described Norwegian policymakers as 'sitting on the fence' while challenges were 'queuing up' (MBL, interviewed 2019). In short, the informants described Norway as too small to tackle platform taxation on its own, stressing the need to implement regulation at an international level. In terms of creating policy windows, informants identified the problem but did not see it as 'solvable' (Zahariadis, 2014) by national policymakers. However, other countries have engaged in nation-specific regulation to counter the negative effects of platforms. For instance, France has implemented temporary digital tax, Germany has amended their antitrust laws to hinder market abuse and Australia has passed a bill that ensures that the news media will be remunerated for the content 
available on digital platforms. At the time of the interviews, fewer such examples existed, narrowing the action frames informants saw as possible.

According to informants, a primary channel for political regulation was the EU system, even though Norway is not a full member. Consequently, all our informants pointed towards international industry collaborations and agreements to exercise pressure and come up with reasonable policy solutions. As one informant said, 'It doesn't help with Norwegian rules when someone from the outside gets a dominating position. [The] EU is crucial for Norwegian media policy’ (MBL, interviewed 2019). Similarly, another informant explained,

It's exceptionally complex problems that need to be solved over time. The Nordic countries are in an excellent position to have a say, because everybody can see that we have well-functioning societies. Together, we have the potential to influence, because even if Norway is not part of the EU, Sweden, Denmark and Finland are. (Schibsted, interviewed 2019)

As this quote indicates, to regulate global platforms is seen as difficult, but possible. Through collaboration, a possible policy window was envisaged.

\section{Conclusion: small, but not powerless}

This article explores how media actors in a small state respond to asymmetrical power dynamics induced by global platforms (Nielsen and Ganter, 2018). By combining perspectives from platform studies with the MPF approach (Steen-Johnsen et al., 2019), it investigates how media actors manoeuvre to defend their positions in a disruptive field and how these actions are contextualised by more deeply entrenched market structures. Following Puppis (2009), our starting point is that small nations, defined in terms of population size and small media markets, often benefit from close bonds between elites and consensus-driven policy processes (p. 5). At the same time, smallness is always relational, and it is therefore necessary to explore how the position can be played out in different industry-policy contexts.

Our study documents how asymmetrical power is framed around the common destiny of being a 'small' media market. 'Small', in this context, is used as a unifier to address common challenges across the media field and it is contextualised in terms of not only how it impacts the media sector but also how it threatens key democratic values, such as trust and transparency. The cultural values entrenched in digital platforms previously emphasised by a wide range of scholars (Jin, 2020; Van Dijck et al., 2018), play a crucial part in how collective frames are constructed nationally. The strong sense of 'we are in this together' is used specifically to highlight the importance of collaborations among industry players and for securing existing subsidy schemes and policy initiatives targeted at national media industry players. Of course, 'being small' is not unique to media actors in small nations in the context of global platform power. Due to the all-encompassing power these platforms represent, all media companies and media markets are 'small'. However, in nations with small populations, 'smallness' has historically been used to legitimise interventionist media regulation regimes, even before platform power. Consequently, the collective framing has historical roots and can 
arguably have a stronger impact when it comes to utilising national policy windows. The study has documented how national media actors have been effective in transforming existing policy incentives to encompass digital products, for instance, through the media support scheme or the zero-VAT. Consequently, Flew's et al. (2016) argument that national government still has an important part to play is supported by our study and can partly explain why the digital transformation in the media sector in Norway has, in many respects, been successful. We find, however, little confidence among industry players that tax regulation of global platforms can take place at the national level due to a lack of knowledge and competence among Norwegian politicians. This, in turn, stresses the importance of building international alliances to increase pressure at the EU level. As Puppis (2009) argue, seeking a companion is useful when one has less influence alone. However, as referred to above, other nations have managed to implement regulations, and as such, the Norwegian attitude might be somewhat defensive. At the time of the interviews, Norwegian media actors interpreted that the most viable possibility for a policy window was through the EU, due to the lack of knowledge and skills of Norwegian political actors, and consequently placed their efforts where it was deemed most efficient. Recent developments, however, indicate a closer dialogue between policy-makers and the industry about the issue.

At another level, our study documents that asymmetrical power and 'being small' does not entail the same things for all national players. Mirroring the findings of Meese and Hurcombe (2020) and Nielsen and Ganter (2018), we found that size and market position impacts the level of dependency on global platforms which leads to different action logics. For the market leader, Schibsted, keeping an 'arm's length' was understood to be the wisest move and served as a mobilising tool for developing competing technologies. For those who entered closer ventures with global platforms, it was imperative to develop specific skills to avoid being 'held hostage'. Our study also uncovers renewed tensions between national players, especially when it comes to the role of the public service institution. Commercial industry players commonly critiqued NRK for not being loyal when distributing content on global platforms. The public service institution, on its side, defended its actions based on their mandate of meeting people where they are. The criticism must be understood in a historical context where private actors routinely question the dominant position of the public service broadcaster; however, they have so far failed to make substantial limitations to their mandate.

On a final note, the case study at hand illustrates how Norwegian companies have managed to join forces when necessary to take advantage of what has been defined as a shared problem, while they at the same time seek individual industry solutions. An important insight is how collective frames simultaneously can be used within and across industries, and how they lead to specific action logics. Being small, we argue, must not be confused with being powerless. Rather, it can be understood as a skill that can be used to achieve certain goals, also when encountering global platform power.

\section{Funding}

The author(s) disclosed receipt of the following financial support for the research, authorship, and/or publication of this article: The study was funded by the Norwegian Research Council (KULMEDIA programme), grant number 259161. 


\section{ORCID iD}

Karoline Andrea Ihlebæk iD https://orcid.org/0000-0003-3150-9005

\section{Notes}

1. Puppis (2009) further summarises that the term 'small states' should apply to nations with less than 18 million habitants (p. 11).

2. We would like to thank the anonymous reviewers that gave such thorough and insightful comments. We are truly grateful. We would also like to thank all the members of the research project 'Disruptive Change and New Media Policies: A Field Approach'.

3. Titles are from when the interviews were conducted.

4. Interview requests were also sent to Netflix, YouTube and Google, who declined to take part in the study.

\section{References}

Amedia (2017) Response to Government White Paper on Media Diversity, 23. June. Oslo: Amedia. Andrews L (2019) Facebook, the Media and Democracy. Kindle ed. Oxon: Taylor \& Francis.

Brüggemann M, Humprecht E and Nielsen RK (2016) Framing the newspaper 'crisis': how debates on the state of the press are shaped in Finland, France, Germany, Italy, United Kingdom and United States. Journalism Studies 17(5): 533-551.

Bucher T (2018) If . . Then: Algorithmic Power and Politics. Oxford: Oxford University Press.

Cammaerts B and Mansell R (2020) Digital platform policy and regulation: toward a radical democratic turn. International Journal of Communication 14: 135-154.

DiMaggio PJ and Powell WW (1983) The iron cage revisited: institutional isomorphism and collective rationality in organisational fields. American Sociological Review 48(2): 147-160.

Donders K (2013) Fighting a (lost) battle? An analysis of 20 years of private television complaints against the funding of public service broadcasting. In: Donders K, Pauwels $\mathrm{C}$ and Loisen $\mathrm{J}$ (eds) Private Television in Western Europe: Content, Market, Policies. New York: Palgrave MacMillan, pp. 214-228.

Doyle G (2013) Understanding Media Economics. 2nd ed. London: SAGE.

Ekeberg E (2019) Amedia og Aller Media tar opp annonsekampen mot Google og Facebook: Oppretter eget selskap. Dagens Neringsliv, 21 June. Available at: https://www.dn.no/ reklame/aller-media/amedia/dag-sorsdahl/amedia-og-aller-media-tar-opp-annonsekampenmot-google-og-facebook-oppretter-eget-selskap/2-1-625425

Enli G, Raats T, Syvertsen T, et al. (2019) Media policy for private media in the age of digital platforms. European Journal of Communication 34(4): 395-409.

Evens T and Donders K (2018) Platform Power and Policy in Transforming Television Markets. London: Palgrave MacMillan.

Flew T, Iosifidis P and Steemers J (2016) Global Media and National Policies. The Return of the State. London: Palgrave MacMillan.

Fligstein N and McAdam D (2011) Toward a general theory of strategic action fields. Sociological Theory 29(1): 1-26.

Freedman D (2008) The Politics of Media Policy. Cambridge: Polity Press.

Freedman D (2010) Media policy silence: the hidden face of communications decision making. The International Journal of Press/Politics 15(3): 344-361.

Galloway S (2017) The Four: The Hidden DNA of Amazon, Apple, Facebook, and Google. New York: Portfolio, Penguin.

Gillespie T (2010) The politics of 'platforms'. New Media \& Society 12(3): 347-364. 
Gillespie T (2018) Custodians of the Internet: Platforms, Content Moderation, and the Hidden Decisions That Shape Social Media. New Haven, CT: Yale University Press.

Hallin DC and Mancini P (2004) Comparing Media Systems. Three Models of Media and Politics. Cambridge: Cambridge University Press.

Herzog C, Handke C and Hitters E (2019) Analysing talk and text II: thematic analysis. In: Van den Bulck H, Puppis M, Donders K, et al. (eds) The Palgrave Handbook of Methods for Media Policy Research. London: Palgrave MacMillan, pp. 385-401.

Jin DJ (2020) Globalization and the Media in the Digital Platform Age. New York: Routledge.

Karppinen K and Moe H (2019) Texts as data I: document analysis. In: Van den Bulck H, Puppis M, Donders K, et al. (eds) The Palgrave Handbook of Methods for Media Policy Research. London: Palgrave MacMillan, pp. 249-262.

Kingdon JV (1995) Agendas, Alternatives, and Public Polities. 2nd ed. New York: HarperCollins.

Lawrence TB and Suddaby R (2006) Institutions and institutional work. In: Clegg SR, Hardy $\mathrm{C}$ and Lawrence TB (eds) The SAGE Handbook of Organization Studies. 2nd ed. London: SAGE, pp. 215-254.

Lobato R (2019) Netflix Nations. The Geography of Digital Distributions. New York: New York University Press.

Mansell R (2021) European responses to (US) digital platform dominance. In: Jin AY (ed.) The Routledge Handbook of Digital Media and Globalization. New York: Routledge, pp. 141-150.

Mansell R and Steinmueller WE (2020) Advanced Introduction to Platforms Economies. Cheltenham: Edward Elgar Publishing.

MBL (2017) Response to Government White Paper on Media Diversity, 22 June. Oslo: MBL.

Meese J and Hurcombe E (2020) Facebook, news media and platform dependency: the institutional impacts of news distribution on social platforms. New Media \& Society. Epub ahead of print 3 June. DOI: 10.1177/1461444820926472.

Meld. St. 15 (2016-2017) Eit moderne og framtidsretta NRK - Finansiering og innhaldsplikter. Oslo: KUD.

Meld. St. 17 (2018-2019) Mangfald og armlengdes avstand. Mediepolitikk for ei ny tid. Oslo: KUD.

Meld. St. 38 (2014-2015) Open og opplyst. Allmennkringkasting og mediemangfold. Oslo: KUD.

Mintrom M and Norman P (2009) Policy entrepreneurship and policy change. Policy Studies Journal 37(4): 649-667.

Nielsen RK and Ganter SA (2018) Dealing with digital intermediaries: a case study of the relations between publishers and platforms. New Media \& Society 20(4): 1600-1616.

NOU (2010:14) Lett å komme til orde, vanskelig å bli hørt-en moderne mediestøtte. Oslo: NOU.

NOU (2017:7) Det norske mediemangfoldet. En styrket mediepolitikk for borgerne. Oslo: NOU.

NRK (2017) Response to Government White Paper on Media Diversity, 22 June. Oslo: NRK.

Ots M and Krumsvik AH (2016) Media policy's new challenges. Journal of Media Business Studies 13(3): 125-127.

Plantin JC (2019) Review essay: how platforms shape public values and public discourse. Media, Culture \& Society 41(2): 252-257.

Plantin J-C, Lagoze C, Edwards PN, et al. (2018) Infrastructure studies meet platform studies in the age of Google and Facebook. New Media \& Society 20(1): 293-310.

Puppis M (2009) Media regulation in small states. International Communication Gazette 71(1): $7-17$.

Rashidian N, Tsiveriotis G, Brown P, et al. (2019) Platforms and Publishers: The End of an Era. New York: Tow Centre for Digital Journalism. Available at: https://www.cjr.org/tow_center_ reports/platforms-and-publishers-end-of-an-era.php (accessed 29 January 2020).

Richard D (1996) Elite interviewing: approaches and pitfalls. Politics 16(3): 199-204. 
Schibsted (2017) Response to Government White Paper on Media Diversity, 23 June. Oslo: Schibsted.

Sjøvaag H and Krumsvik A (2017) In search of Journalism Funding: scenarios for future media policy in Norway. Journalism Practice 12(9): 1201-1219.

Srmicek N (2017) Platform Capitalism. Cambridge, MA; Malden, MA: Polity Press.

Steen-Johnsen K, Sundet VS and Enjolras B (2019) Theorizing policy-industry processes: a media policy field approach. European Journal of Communication 34(2): 190-204.

Steinberg M (2019) The Platform Economy: How Japan Transformed the Consumer Internet. Minneapolis, MN: University of Minnesota Press.

Sundet VS (2021) Television Drama in the Age of Streaming. Transnational Strategies and Digital Production Cultures at the NRK. London: Palgrave.

Sundet VS and Syvertsen T (2021) From problem to solution? Why it is difficult to restrict the remit of public broadcasters. International Journal of Cultural Policy 27(4): 499-512.

Sundet VS, Ihlebæk KA and Steen-Johnsen K (2020) Policy windows and converging frames: a longitudinal study of digitalization and media policy change. Media, Culture \& Society 42(5): 711-726.

Syvertsen T, Enli G, Mjøs OJ, et al. (2014) The Media Welfare State. Nordic Media in the Digital Age. Ann Arbor, MI: The University of Michigan Press.

Van Audenhove L and Donders K (2019) Talking to People III: expert interviews and Elite Interviews. In: Van den Bulck H, Puppis M, Donders K, et al. (eds) The Palgrave Handbook of Methods for Media Policy Research. London: Palgrave MacMillan, pp. 179-197.

Van den Bulck H and Donders K (2014) Analyzing European media policy: stakeholders and advocacy coalitions. In: Donders K, Pauwels C and Loisen J (eds) The Palgrave Handbook of European Media Policy. London: Palgrave, pp. 16-35.

Van Dijck J, Poell T and de Waal M (2018) The Platform Society. Public Values in a Connective World. Oxford: Oxford University Press.

Zahariadis N (2014) Ambiguity and multiple streams. In: Sabatier PA and Weible CM (eds) Theories of the Policy Process. 3rd ed. Boulder, CO: Westview Press, pp. 27-58.

\section{Author biographies}

Karoline Andrea Ihlebæk (PhD) is an associate professor in journalism at Oslo Metropolitan University where she is part of the Digital Journalism Research Group (DJRG). She is an affiliated researcher at the Centre for Research at Extremism (C-REX) and the Centre for the Study of Political Communication (POLKOM) at the University of Oslo. Her research interests include media policy, platforms, journalism and alternative media.

Vilde Schanke Sundet $(\mathrm{PhD})$ is a researcher in media and communication at the University of Oslo, Norway. She has published extensively on topics concerning media industries, television production, media policy and audiences/fans. She has recently published a book Television drama in the age of streaming (Palgrave, 2021). 